\title{
EARLY CARDIAC ABNORMALITIES AND SERUM N-TERMINAL PRO B-TYPE NATRIURETIC PEPTIDE LEVELS IN OBESE CHILDREN
}

\author{
F. Battal ${ }^{1}$, B. Ermis ${ }^{2}$, Z. Aktop ${ }^{1}$, M. Can ${ }^{1}$, F. Demirel ${ }^{3}$ \\ ${ }^{1}$ Karaelmas University, Zonguldak, ${ }^{2}$ Sakarya University, Sakarya, ${ }^{3}$ Ankara Children's Health and Diseases \\ Hematology Oncology Hospita, Ankara, Turkey
}

Objective: The aim of this study was to evaluate early cardiac abnormalities in obese children by the conventional echocardiography. This study also aimed to investigate the serum N-terminal pro B-type natriuretic peptide (NT-ProBNP) levels in obese children.

Methods: We started this study by 68 obese children and 35 healthy controls matched for age and sex. Body mass index (BMI) was calculated. Children with a BMI $\geq 95^{\text {th }}$ percentile were considered obese. Thirty children in obese group were also diagnosed as metabolic syndrome according to the IDF (International Diabetes Federation) criteria. Standard echocardiographic study was performed on each patient and control subject. Diastolic filling parameters were evaluated using pulsed-wave tissue Doppler method. Blood samples were taken at 8 o'clock (a.m.) to study blood biochemistry tests, including insulin, lipids, glucose and NT-ProBNP. Serum NT-ProBNP levels were measured by a solid-phase, enzyme-labeled chemiluminescent immunometric assay. Homeostasis model assessment of insulin resistance (HOMA-IR) was calculated. Children with a HOMA-IR > 3.16 were considered insulin resistant.

Results: There were diastolic filling abnormalities in obese children, as shown by a decrease E/A ratio and a prolongation in E-wave deceleration time. The levels of NT-ProBNP were not statistically different among the groups. The levels of NT-ProBNP were not different between obese children with and without metabolic syndrome and those with and without hypertension, respectively.

Conclusion: Although there were diastolic filling abnormalities in obese children, NT-ProBNP levels of whom were not different from healthy controls. 